\title{
Synthesis and Characterization of Optically Active Fractal Seed Mediated Silver Nickel Bimetallic Nanoparticles
}

\author{
Joseph Adeyemi Adekoya, ${ }^{1,2}$ Enock Olugbenga Dare, ${ }^{3}$ \\ Michael Adediran Mesubi, ${ }^{4}$ and Neerish Revaprasadu ${ }^{2}$ \\ ${ }^{1}$ Department of Chemistry, Covenant University, PMB 1023, Ota, Ogun 112, Nigeria \\ ${ }^{2}$ Department of Chemistry, University of Zululand, Private Bag X1001, Kwadlangezwa 3886, South Africa \\ ${ }^{3}$ Department of Chemistry, Federal University of Agriculture, PMB 2240, Alabata Road, Abeokuta 110001, Nigeria \\ ${ }^{4}$ Department of Chemistry, Kwara State University, PMB 1530, Ilorin 23437, Nigeria
}

Correspondence should be addressed to Joseph Adeyemi Adekoya; joseph.adekoya@covenantuniversity.edu.ng

Received 20 December 2013; Accepted 6 February 2014; Published 11 March 2014

Academic Editor: Iwan Kityk

Copyright (C) 2014 Joseph Adeyemi Adekoya et al. This is an open access article distributed under the Creative Commons Attribution License, which permits unrestricted use, distribution, and reproduction in any medium, provided the original work is properly cited.

\begin{abstract}
The synthesis of new seed mediated AgNi allied bimetallic nanocomposites was successfully carried out by the successive reduction of the metal ions in diethylene glycol, ethylene glycol, glycerol, and pentaerythritol solutions, with concomitant precipitation of $\mathrm{Ag} / \mathrm{Ni}$ bimetal sols. The optical measurement revealed the existence of distinct band edge with surface plasmon resonance (SPR) in the region of 400-425 $\mathrm{nm}$ and excitonic emission with maximum peak at $382 \mathrm{~nm}$ which were reminiscent of clusterin-cluster surface enriched bimetallic silver-nickel sols. The morphological characterization by transmission electron microscopy, high resolution transmission electron microscopy, and X-ray diffraction analyses complimented by surface scan using X-ray photoelectron spectroscopy strongly supported the formation of intimately alloyed face-centered silver/nickel nanoclusters.
\end{abstract}

\section{Introduction}

The synthesis of new materials and the investigation of their characteristic properties is a noble aspect of nanochemistry due to the fact that various applications have been found for these materials in electronics, sensor, optical devices, waveguide, and fibre optics to mention a few. As a result, immense effort directed at synthesizing and manipulating the size, size distribution, and shape of these nanoparticles is inexhaustive. In particular, silver nanoparticles have been largely prepared and evaluated for sensor, optical, and antimicrobial properties. However, the nanocomposite silver nickel is being considered due to its synergistic effect which offers a wide range of applications that include catalysis. Monodispersed allied silver/nickel nanoparticles have been prepared using various chemical routes based on hydrolytic reduction of the metal ions followed by polycondensation of the reduced nuclei. The reactions are largely thermodynamically driven with respect to temperature and time to produce uniformly distributed nanosized particles.
There are a number of literature reports on AgNi nanoparticles; Xiao and coworkers presented an approach in which laser ablation was used in the deposition silver/nickel bimetallic nanoparticles; the laser was a pulsed Nd:YAG laser source $[1,2]$. The effective nonlinear absorption of $\mathrm{Ni} / \mathrm{Ag}$ nanoparticles was found to be higher than that of pristine Ag nanoparticles. The nanoparticles were synthesized via wet chemical reduction in $\mathrm{C}_{19} \mathrm{H}_{42} \mathrm{BrN}$ (CTAB) matrix, hydrazine hydrate being the reducing agent, and it was found to be a very potent material for optical limiting and photonic applications in the work of Kishore et al., 2012 [3].

Likewise, one-step facile synthetic route was also devised for the preparation of well-dispersed $\mathrm{Ag} / \mathrm{Ni}$ core-shell nanoparticles with uniform and intact shells. The process was performed by the reduction of silver nitrate and nickel nitrate with sodium borohydride in water-in-oil (W/O) microemulsions of water/polyoxyethylene, nonylphenol, and polyoxyethylene nonylphenol/n-heptane. The Ag/Ni core-shell nanoparticles showed a high catalytic activity for degradation reaction of eosin $\mathrm{Y}[4]$. 


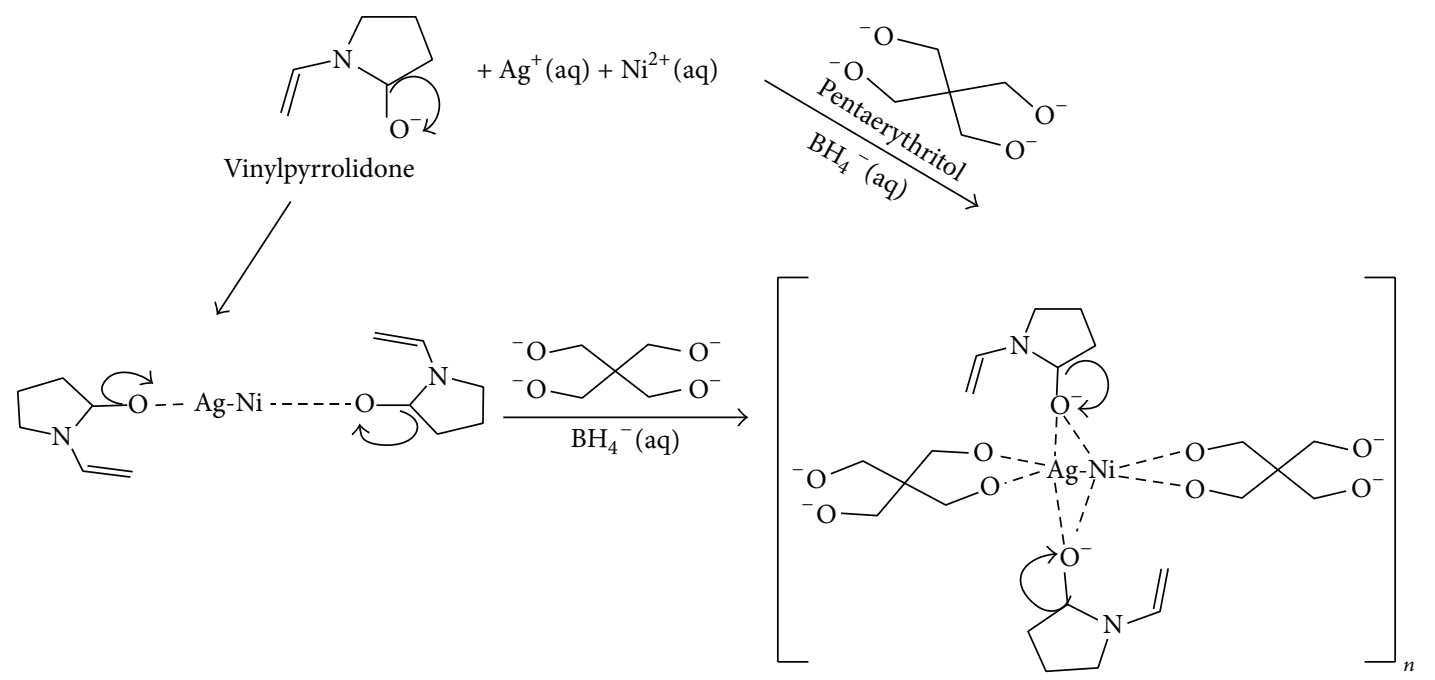

SCHEME 1: Scheme of reaction for the formation of $\mathrm{Ag} / \mathrm{Ni}$ nanocluster prior to anisotropic nucleation and particle growth.

So, also, Lee and Chen have successfully prepared NiAg core-shell nanoparticles by successive hydrazine reduction of metal salts in ethylene glycol without the addition of protective agents. To prohibit the particles from coalescing, the appropriate nickel concentration for the coating of Ag nanoshells was less than $1.0 \mathrm{~mm}$. The TEM and XPS surface composition studies indicated that $\mathrm{Ni}$ cores were fully covered by Ag nanoshells. The shell thickness was controlled by the silver nitrate concentration. The EDX and XRD analyses reveal that both $\mathrm{Ni}$ cores and Ag shells have a face-centered cubic structure.

Later on, a synthetic method was developed in which polyethyleneimine (PEI) was used as a protective agent to fabricate $\mathrm{Ni}$-core/Ag-shell ( $\mathrm{NiAg}$ ) nanoparticles. The produced $\mathrm{NiAg}$ nanoparticles were monodispersed, and the core was about $6.2 \mathrm{~nm}$ in diameter, and the shell thickness was about $0.85 \mathrm{~nm}$. In the nickel concentration of $0.25-25 \mathrm{mM}$; the size of the NiAg nanoparticles showed no significant change for different thickness of Ag coating. X-ray photoelectron spectroscopy indicated that both $\mathrm{Ni}$ cores and Ag shells had facecentered-cubic structure, and the Ni cores were fully covered by Ag shells. Moreover, a peak was observed at $430 \mathrm{~nm}$ in the absorption band of the NiAg nanoparticles, which is consistent with the characteristic spectra of Ag nanoparticles. The sample was nearly superparamagnetic. The coating of Ag shells led to a decrease of supersaturation magnetization, which indicated that the $\mathrm{Ni} / \mathrm{Ag}$ interface quenched the magnetic moment. The thermal and XRD analyses also indicated that the Ag shells provided a better protection for $\mathrm{Ni} / \mathrm{Ag}$ nanoparticles as an antioxidant compared to pure Ni nanoparticles [5].

In this work, we have extended earlier approaches to preparing silver/nickel nanoparticles which could be stable over a period of six months by coprecipitating the allied nanoparticles from organic and aqueous phases. The use of chelating organic groups is usually intended to thermodynamically control anisotropic nucleation and particle growth processes.
Thus, the choice of polyols was made primarily considering their nontoxicity and the ability to furnish the base hydrolysis required for the reduction and nucleation process.

\section{Experimental}

The seed mediated or successive addition method was modified from the literature method and used to prepare monodispersed bimetallic AgNi nanoparticles in different polyols at optimum concentration of metal precursors and controlled temperature $[6,7]$. The reactions for the formation of the bimetallic nanoparticles via anisotropic nucleation and growth are shown in Scheme 1.

2.1. Materials. All inorganic salts, solvents, and chemical reagents used were analytical grade and were purchased from Sigma-Aldrich Corporation, UK. They are as follow: silver nitrate, nickel (II) acetate, glycerol, ethylene glycol (EG) and diethylene glycol (DEG), pentaerythritol (PET), poly(vinyl pyrrolidone) (PVP), methanol $(99.5 \% \mathrm{w} / \mathrm{w})$, and ethanol $(99.5 \% \mathrm{w} / \mathrm{w})$.

2.2. Synthesis of Ag/Ni Nanoparticles. The bimetallic nanosized particles of AgNi were prepared by the seed growth or successive addition method [8] as follows: $15 \mathrm{~mL}$ glycerol $(99.5 \% \mathrm{w} / \mathrm{w})$ was measured into a round bottom flask containing a magnetic stirrer, and $(0.03-0.08 \mathrm{mmol})$ PVP was added. Then, the mixture was stirred and gradually heated at the rate of $1.7^{\circ} \mathrm{C} /$ minute to $150^{\circ} \mathrm{C}$. Afterward $(0.41-2.01 \mathrm{mmol})$ $\mathrm{Ni}\left(\mathrm{CH}_{3} \mathrm{CO}_{2}\right)_{2} \cdot 4 \mathrm{H}_{2} \mathrm{O}$ was injected into the hot solution; the colour rapidly changed to Prussian green. After allowing the growth of Ni nanoparticles which sometimes acted as a seed, (0.35-1.24 mmol) $\mathrm{AgNO}_{3}$ was injected into the colloidal mixture and the reaction was continued for 4 hours with continuous stirring. After the hot injection of silver nitrate, pale brown coloured $\mathrm{Ag} / \mathrm{Ni}$ sol was obtained. While hot, the AgNi sol was copiously washed with methanol several times 
and centrifuged at $4400 \mathrm{rpm}$ for $10-15 \mathrm{~min}$. to remove excess unreacted stabilizer. The AgNi sol was later redispersed in ethanol.

Similarly, the aqueous coprecipitation of $\mathrm{Ag} / \mathrm{Ni}$ sol was carried out by using $0.02-0.13 \mathrm{mmol}$ PVP, $24.01-37.25 \mathrm{mmol}$ PET (capping agent), $0.12-0.82 \mathrm{mmol} \mathrm{AgNO}_{3}$, and 0.66$1.48 \mathrm{mmol} \mathrm{Ni}\left(\mathrm{CO}_{2} \mathrm{CH}_{3}\right)_{2} \cdot 4 \mathrm{H}_{2} \mathrm{O}$ in $100 \mathrm{~mL}$ Milliken deionized $\mathrm{H}_{2} \mathrm{O}$ at $90^{\circ} \mathrm{C}$. The procedure was repeated at $160^{\circ} \mathrm{C}, 2$ hours, and $175^{\circ} \mathrm{C}, 2$ hours; and then for ethylene glycol at $160^{\circ} \mathrm{C}, 3$ hours, and $175^{\circ} \mathrm{C}, 2$ hours; diethylene glycol at $190^{\circ} \mathrm{C}$, 2 hours, and at $200^{\circ} \mathrm{C}, 2$ hours. The difference in colour indicated the formation of different AgNi nanoparticles.

2.3. Isolation of $\mathrm{Ag} / \mathrm{Ni}$ Nanoparticles. The centrifuged sols obtained after decantation were redispersed in double distilled ethanol and cleaned in ultrasonic bath at $50^{\circ} \mathrm{C}$ for 60 minutes before further characterization.

\subsection{Characterization}

2.4.1. Optical Characterization. A Varian Cary 50 Conc UVVis spectrophotometer was used to carry out the optical measurements and the samples were placed in silica cuvettes $(1 \mathrm{~cm}$ path length), using ethanol as a reference solvent. A PerkinElmer LS 55 Luminescence spectrometer was used to measure the photoluminescence of the particles. The samples were placed in a quartz cuvette $(1 \mathrm{~cm}$ path length).

2.4.2. Structural Characterization. The crystalline phase was identified by XRD, employing a scanning rate of $0.05^{\circ} \mathrm{min}^{-1}$ in a $2 \theta$ range from 20 to $80^{\circ}$, using a Bruker AXS D8 diffractometer equipped with nickel filtered $\mathrm{Cu} \mathrm{K} \alpha$ radiation $(\lambda=1.5406 \AA)$ at $40 \mathrm{kV}, 40 \mathrm{~mA}$, and at room temperature. The morphology and particle sizes of the samples were characterized by a JEOL 1010 TEM with an accelerating voltage of $100 \mathrm{kV}$, Megaview III camera, and Soft Imaging Systems iTEM software. The detail morphological and structural features were investigated using HRTEM images with a JEOL 2010 TEM operated at an accelerating voltage of $200 \mathrm{kV}$.

The survey of surface property and high resolution spectra of nanoparticles were collected using XPS PHI 5000 Versaprobe-Scanning ESCA Microprobe, with $100 \mu \mathrm{m} 25 \mathrm{~W}$ $15 \mathrm{kV}$ Al monochromatic X-ray beams.

\section{Results and Discussion}

The polyol stabilized nanoparticles were very stable both in the liquid and solid phases. The stability was checked by following the absorbance spectra over extended periods of six months and reproducible absorption maxima were obtained typical of $\mathrm{Ag} / \mathrm{Ni}$ sol property. The oxo groups present in the vinylpyrrolidone stabilized by the bimetallic nanoparticles as proposed by Veronese, 2001 [9]. The use of sodium borohydride resulted in fast reduction of metal ions when pentaerythritol was used as a capping agent in the aqueous phase synthesis of $\mathrm{Ag} / \mathrm{Ni}$ sols.

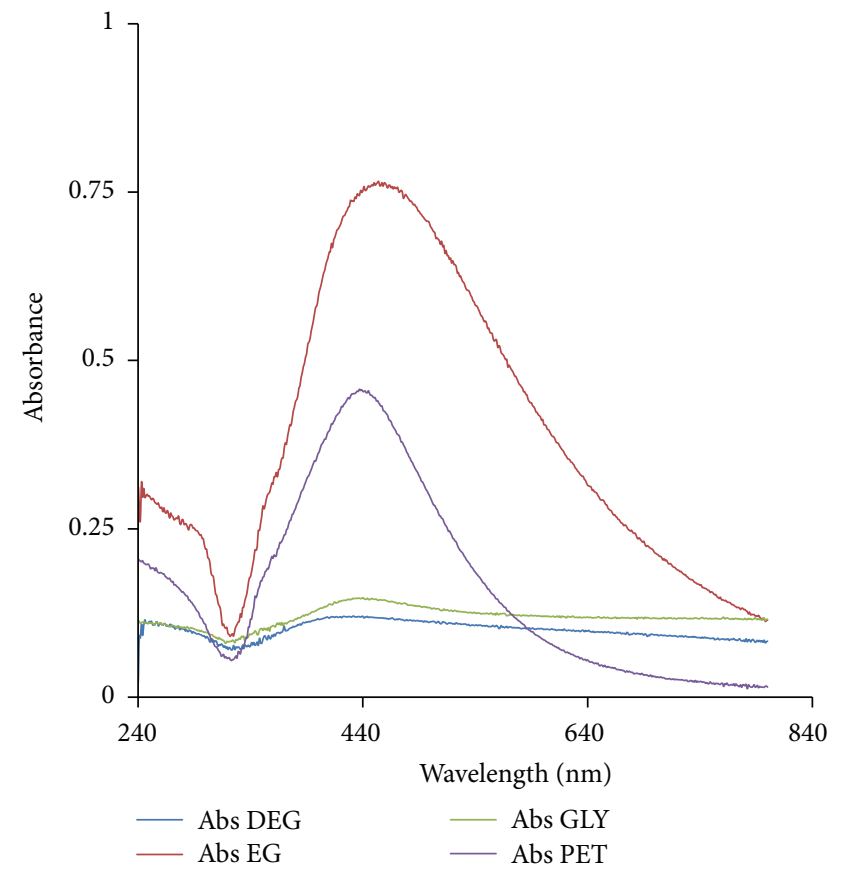

Figure 1: Absorbance Spectra of AgNi sols with different stabilizer/capping agents: $\mathrm{PVP} / \mathrm{DEG}$ at $190^{\circ} \mathrm{C}, 2 \mathrm{~h}$; PVP/EG at $175^{\circ} \mathrm{C}, 2 \mathrm{~h}$; $\mathrm{PVP} / \mathrm{GLY}$ at $175^{\circ} \mathrm{C}, 2 \mathrm{~h} ; \mathrm{PVP} / \mathrm{PET}$ at $90^{\circ} \mathrm{C}, 2 \mathrm{~h}$.

3.1. Optical Properties of Ag/Ni Sols. The UV-Visible characterization of the prepared bimetallic AgNi cluster was carried out in absolute ethanol and the spectra recorded for various mole ratios of metal precursors and stabilizer are presented in Figure 1.

In all, there was a clear evidence of surface plasmon band (SPB) occurring at $416.04 \mathrm{~nm}, 438.96 \mathrm{~nm}, 452.00 \mathrm{~nm}$, and $436.97 \mathrm{~nm}$ for PVP/DEG, PVP/GLY, PVP/EG, and PVP/PET stabilized/capped sols, respectively (Figure 1), which was similar to the maximum wavelength of absorption of monometallic Ag nanoparticles. This suggests that the surface of the bimetallic nanoparticles is enriched with $\mathrm{Ag}$, and there is a possible existence of a core-shell structure as reported in previous studies $[3,4]$.

Furthermore, change in temperature and time of reaction as expected caused a shift in the maximum wavelength of AgNi PVP/EG synthesized at $175^{\circ} \mathrm{C}, 2 \mathrm{~h}$, and at $160^{\circ} \mathrm{C}, 3 \mathrm{~h}$ (Figure 2).

There was a corresponding blue shift in absorbance wavelength from 452.0 to $430.0 \mathrm{~nm}$. Similarly, Ag/Ni PVP/PET synthesized at $90^{\circ} \mathrm{C}, 4 \mathrm{~h}$ and $2 \mathrm{~h}$ (Figure 3), exhibited a shift in maximum wavelength from 437 to $436 \mathrm{~nm}$, respectively. The latter on each occasion exhibits a narrow peak with a higher intensity, which often results to particles with a lower aspect ratio.

Photoluminescence (PL) measurements were done for the prepared AgNi sols at a very dilute concentration. The PL spectra, Figures 4 and 5, show that there is an emission of appropriate quantum yield indicated by high fluorophores intensity. 


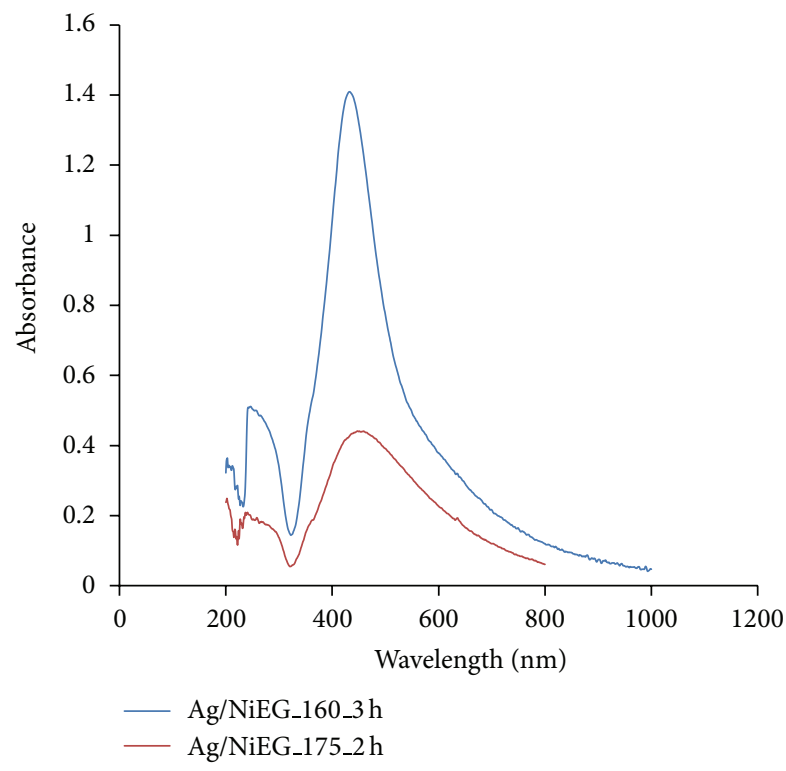

FIGURE 2: Effect of change in temperature and time of reaction on the absorbance property of $\mathrm{Ag} / \mathrm{Ni}$ sols passivated with PVP/EG at $160^{\circ} \mathrm{C}, 3 \mathrm{~h}$ and $175^{\circ} \mathrm{C}, 2 \mathrm{~h}$.

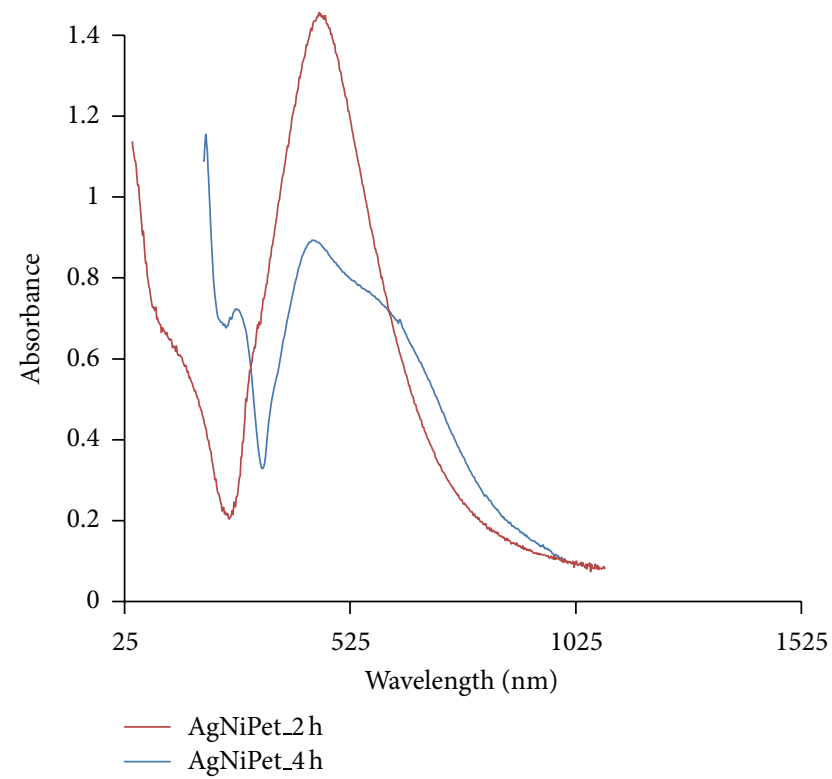

FIGURE 3: Effect of change in temperature and time of reaction on the absorbance property of $\mathrm{Ag} / \mathrm{Ni}$ sols capped with $\mathrm{PVP} / \mathrm{PET}$ at $90^{\circ} \mathrm{C}$, $4 \mathrm{~h}$, and $90^{\circ} \mathrm{C}, 2 \mathrm{~h}$.

In all, the emission wavelength was independent of excitation wavelength, indicating a fluorescence property. For an excitation at $320 \mathrm{~nm}$, the AgNi PVP/EG synthesized at $175^{\circ} \mathrm{C}$, $2 \mathrm{~h}$, and $160^{\circ} \mathrm{C}, 3 \mathrm{~h}$ (Figure 4 ), and exhibited an emission at 382 and $379 \mathrm{~nm}$, respectively. Whereas a slight increase in emission wavelength was observed for AgNi NPs stabilized with PVP/GLY at $160^{\circ} \mathrm{C}, 2 \mathrm{~h}$, and $150^{\circ} \mathrm{C}, 4 \mathrm{~h}$ (Figure 5). AgNi

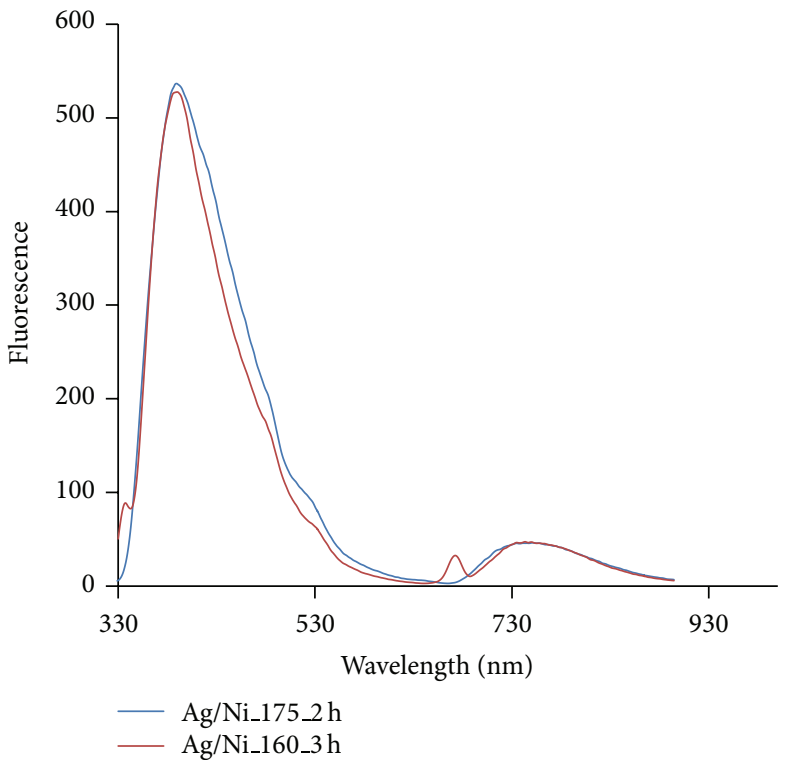

FIgUre 4: PL emission Spectra of AgNi NPs stabilized with PVP/EG at $175^{\circ} \mathrm{C}, 2 \mathrm{~h}$ (blue), and $160^{\circ} \mathrm{C}, 3 \mathrm{~h}$ (red).

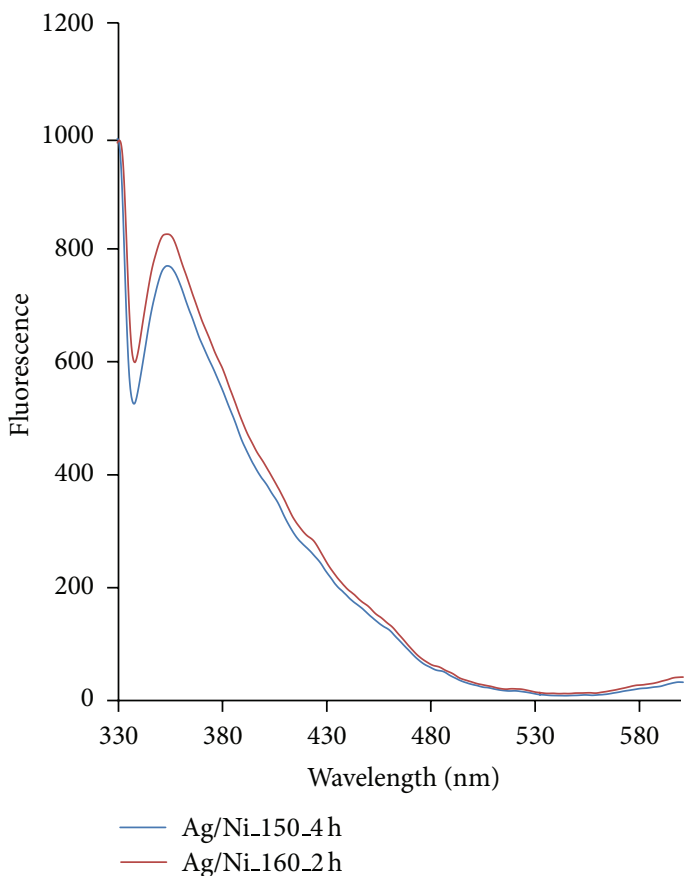

FIgURE 5: PL emission Spectra of AgNi NPs stabilized with $\mathrm{PVP} / \mathrm{GLY}$ at $160^{\circ} \mathrm{C}, 2 \mathrm{~h}$ (red), and $150^{\circ} \mathrm{C}, 4 \mathrm{~h}$ (blue).

NPs were found to emit at 345 and $350 \mathrm{~nm}$, respectively. The emission band edges were close to the absorption band edges in all the optical spectra considered; thus further indicating the fluorescence property of the prepared $\mathrm{Ag} / \mathrm{Ni}$ nanoparticles. However, the fluorescence emission of PVP/PET functionalized AgNi sols (Figure 6) excited at $340 \mathrm{~nm}$ occurred at $392 \mathrm{~nm}$ which was relatively close to the emission peak of Ag 


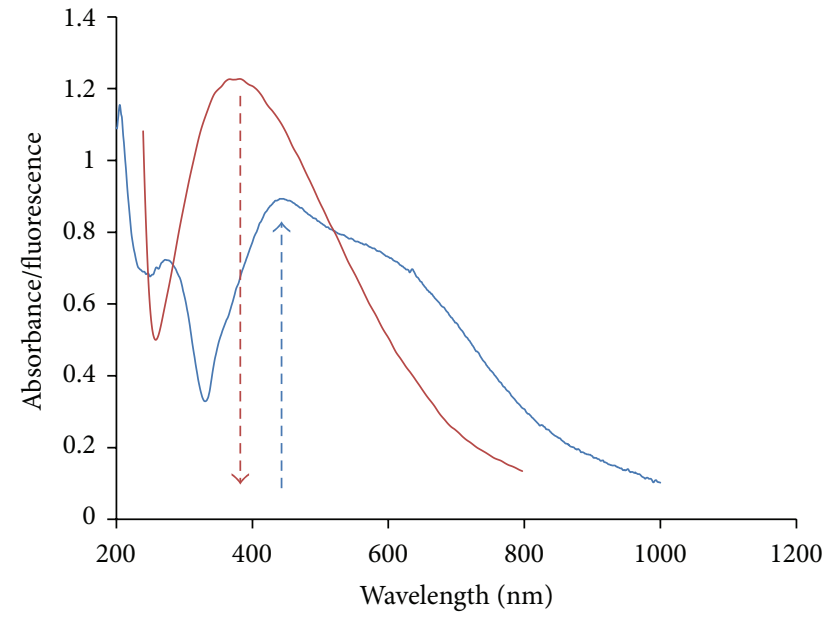

Figure 6: Combined UV-Vis/PL emission spectra of AgNi NPs stabilized with $\mathrm{PVP} / \mathrm{PET}$ at $90^{\circ} \mathrm{C}, 4 \mathrm{~h}$, showing relative position of electronic transition (blue) and emission due to $\mathrm{S}_{1}-\mathrm{S}_{0}$ transition (red).

sols. It was observed that fluorophore emission occurred in $\mathrm{Ag} / \mathrm{Ni}$ just before the corresponding absorbance at $440 \mathrm{~nm}$ due to spin orbit coupling [10].

The optimum mole ratios for the coprecipitation reactions that produced AgNi sols from different metal precursors/stabilizer media occurred at the stoichiometry ratio of $12: 14: 1,13: 17: 1$, and $11: 17: 1$ for $\mathrm{AgNi} / \mathrm{PVP} / \mathrm{EG}, \mathrm{AgNi} /$ $\mathrm{PVP}_{\mathrm{GLY}}$, and $\mathrm{AgNi} / \mathrm{PVP}_{\mathrm{DEG}}$, respectively. At this mole ratio the nanoparticles formed colloidal dispersion which was easily redispersed in ethanol for the optical absorbance of $\mathrm{Ag} / \mathrm{Ni}$ sols to be determined.

The absorption band gaps of the $\mathrm{Ag} / \mathrm{Ni}$ sols were also estimated by the direct band gap method [11] and were found to be $2.83 \mathrm{eV}(438.96 \mathrm{~nm}, t=2 \mathrm{~h}), 2.98 \mathrm{eV}(416.04 \mathrm{~nm}, t=$ $2 \mathrm{~h}), 2.74 \mathrm{eV}(452.00 \mathrm{~nm}, t=2 \mathrm{~h})$, and $2.84 \mathrm{eV}$ (436.97 nm, $t=$ $2 \mathrm{~h})$ for PVP/GLY, PVP/DEG, PVP/EG, and PVP/PET functionalized $\mathrm{Ag} / \mathrm{Ni}$ nanoparticles, respectively. The absorption edges were red-shifted from that of $\mathrm{Ag}$ and Ni bulk crystals given as $3.99 \mathrm{eV}[12,13]$ and $5.2 \mathrm{eV}[14]$, respectively.

3.2. Morphology of AgNi Sols. The TEM images of the prepared AgNi sols as shown in the images in Figures 7 and 8 revealed the existence of a well dispersed, nearly uniform sized spherical, and cube shaped AgNi nanoparticles. The HRTEM images confirmed the shape, size, and morphology of the AgNi NPs. The average size measured for AgNi NPs stabilized with PVP/GLY at $160^{\circ} \mathrm{C}, 2 \mathrm{~h}$ (Figures $7(\mathrm{a})$ and $7(\mathrm{~b})$ ), was $44.79 \pm 14.7 \mathrm{~nm}$, while the mean size of those stabilized with PVP/DEG at $200^{\circ} \mathrm{C}, 2 \mathrm{~h}$ (Figure $8(\mathrm{a})$ ), was $35.16 \pm$ $14.20 \mathrm{~nm}$. But the average size of PVP/EG passivated AgNi $\mathrm{NPs}$ at $160^{\circ} \mathrm{C}, 3 \mathrm{~h}$ (Figure $8(\mathrm{~b})$ ), measured $65.34 \pm 14.0 \mathrm{~nm}$.

The HRTEM images (Figures $7(\mathrm{c})$ and $7(\mathrm{~d})$ ) confirmed the existence of composite nanoparticles of AgNi. There was an overlap between the lattice planes of $\mathrm{Ag}$ and $\mathrm{Co}$, resulting in the alloy formation observed. As for PVP/DEG stabilized
AgNi NPs (Figure 8(c)) the HRTEM image showed the existence of well crystalline structure with lattice spacing measuring about 2.4 A. However, the HRTEM of the PVP/EG passivated NPs (Figure $8(\mathrm{~d})$ ) showed a darkened edge. The thickness was about $14.46 \mathrm{~nm}$, which is typical of a core-shell structure, and is in agreement with UV-Visible absorbance measurement.

This also confirmed that the surface area of nickel atoms was covered by Ag atoms in the nanocomposites. The anisotropy of particles growth was largely determined by the formation of a critical nucleus which occurred at the reduction potential of the individual metals. Furthermore, according to Wu and Lai, 2004 [15], core-shell structure occurs when a large difference exists in reduction potentials of the composite metal ions. Hence, the mechanism of growth for the AgNi nanoparticles under this condition is reaction limited.

The bimetallic nanoparticles were monodispersed and highly crystalline in PVP/PET polymeric network. The TEM micrograph of AgNi sols (Figure 9(a)) further revealed nanoparticles which were monodispersed with a mean particle size of $32.41 \pm 4.20 \mathrm{~nm}$. There was a clue from the HRTEM image (Figure 9(b)) of the core-shell nature of the $\mathrm{Ag} / \mathrm{Ni}$ nanoparticles in the sense that the core of each quasispherical nanoparticle was occupied by a trigonal structure of about $18.57 \mathrm{~nm}$.

No doubt a silver core was inside a nickel shell. The image also revealed the existence of two particles within a nickel shell which was in agreement with earlier work done to synthesise and characterize AgNi core-shell bimetallic nanoparticles [16]. The mole ratio of metal precursors has been shown previously to contribute to the formation of the core-shell structure [4].

The p-XRD measurements were performed on a Bruker AXS D8 powder diffractometer over a 2-thetar angle of 20$90^{\circ}$ at an angular resolution of $0.02^{\circ}$. The XRD patterns are shown in Figure 10.

Four distinct reflections of PVP/DEG stabilized AgNi NPs were observed at $2 \theta$ values of $38.45^{\circ}, 64.60^{\circ}, 77.66^{\circ}$, and $81.76^{\circ}$ corresponding to $\{111\},\{220\},\{311\}$, and $\{222\}$ crystal planes, respectively. These peaks can be indexed to the cubic structure of metallic Ag, JCPDS, 1974 [17]. In addition, the $\mathrm{XRD}$ analysis also revealed two main characteristic peaks for the $\{111\}$ and $\{220\}$ crystal planes of metallic Ni at $2 \theta=44.62^{\circ}$ and $76.40^{\circ}[18]$.

The characteristic peak of $\mathrm{Ni}$ at $2 \theta=44.62^{\circ}$ corresponding to $\{111\}$ planes possibly overlapped with that for the $\{200\}$ planes of $\mathrm{Ag}$ at $2 \theta=44.54^{\circ}$. Therefore, both Ni cores and Ag shells have a fcc structure. Although, it is known that nickel is easily oxidized to the oxides or hydroxide by water, no oxides or hydroxide such as $\mathrm{NiO}, \mathrm{Ni}_{2} \mathrm{O}_{3}$, and $\mathrm{Ni}(\mathrm{OH})_{2}$ were observed from the phase analysis by XRD, indicating the formation of pure nickel of high crystalline quality. Similar phase characteristic was observed for the XRD pattern of AgNi stabilized with $\mathrm{PVP} / \mathrm{EG}$ at $160^{\circ} \mathrm{C}, 3 \mathrm{~h}$, and PVP/GLY at $160^{\circ} \mathrm{C}, 2 \mathrm{~h}$ (Figure 10). The sizes of these nanocomposites based on XRD measurement at $\{100\}$ plain were $31.64,14.55$, and $18.5 \mathrm{~nm}$ for PVP/DEG, PVP/EG, and PVP/GLY stabilized AgNi nanoparticles, respectively. These 

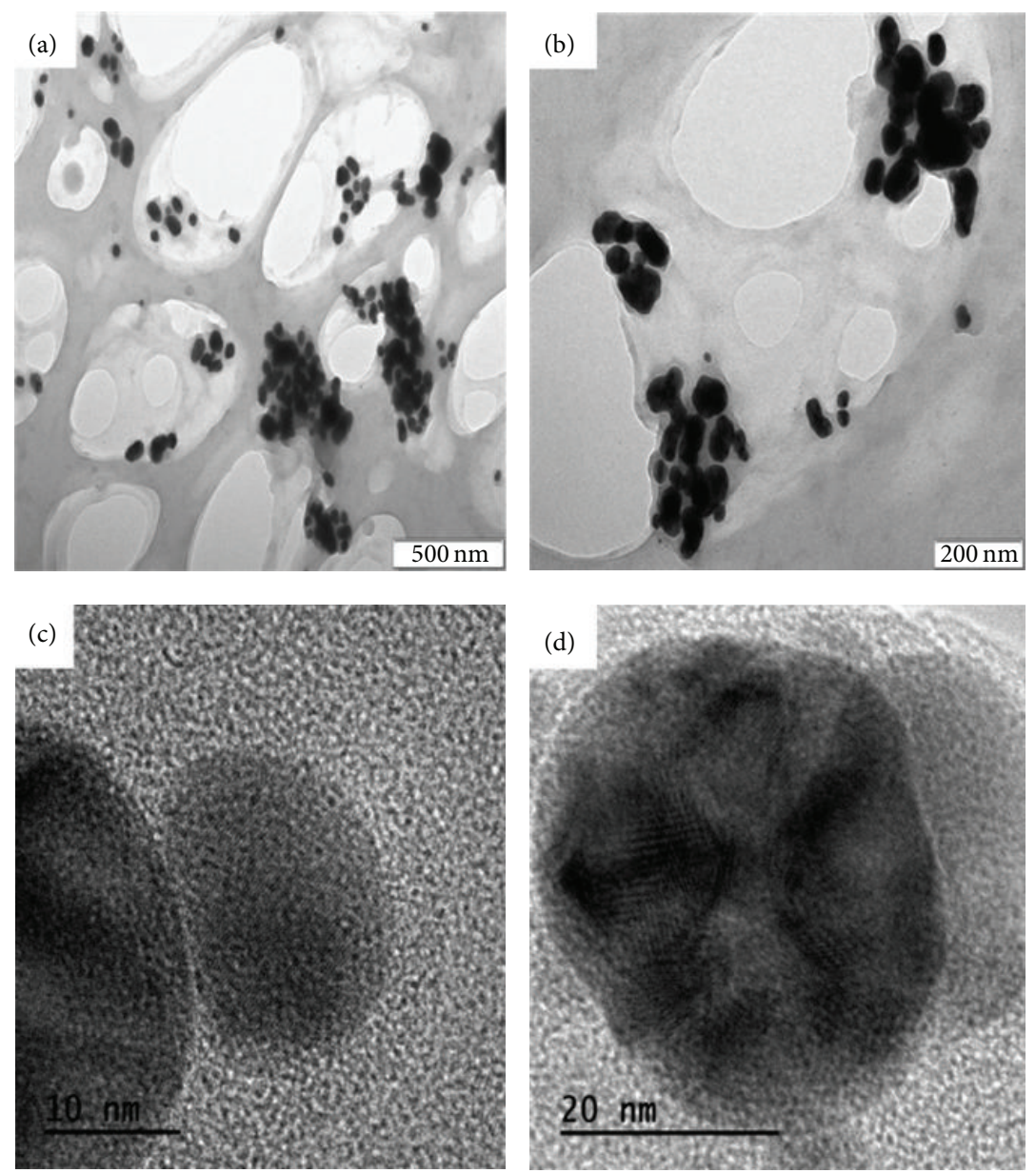

FIGURE 7: ( $a$ and b) TEM images of AgNi NPs stabilized with PVP/GLY at $160^{\circ} \mathrm{C}, 2 \mathrm{~h}$; (c and d) corresponding HRTEM images of (a and b).

values fell within the range of the estimates obtained from TEM measurements.

3.3. XPS Result. The wide area spectrum and the high resolution scans of the core levels of AgNi nanocluster are presented in Figures 11-14.

In order to confirm the existence of the composite nature of AgNi nanoparticles, XPS measurements were carried out with (XPS) PHI 5000 Versaprobe-Scanning ESCA Microprobe, with $100 \mu \mathrm{m} 25 \mathrm{~W} 15 \mathrm{kV} \mathrm{Al}$ monochromatic X-ray beams. The wide area scan (Figure 11), indicated the presence of $\mathrm{Ag}, \mathrm{Ni}, \mathrm{O}, \mathrm{N}$, and $\mathrm{C}$ according to their binding energies, but the characteristic XPS peaks of $\mathrm{Ag}\left(3 \mathrm{~d}_{5 / 2}\right)$ (Figure 12) and $\mathrm{Ni}\left(2 \mathrm{p}_{3 / 2}\right)$ peaks (Figure 13) appeared at $368.45 \mathrm{eV}$ and $852.87 \mathrm{eV}$, respectively $[19,20]$. The surface atomic ratio of $\mathrm{Ag}$ to $\mathrm{Ni}$ in $\mathrm{AgNi}$ was $0.5: 1.6$ which rather confirmed an alloy structure for PVP/DEG stabilized AgNi nanobimetallic particles.

Considering the core levels of Ag (Figure 12) two strong peaks were identified at $\left(3 \mathrm{~d}_{5 / 2}\right) 367.60 \mathrm{eV}$ and $\left(3 \mathrm{~d}_{3 / 2}\right)$ $375.60 \mathrm{eV}$ assigned to $\mathrm{Ag}_{2} \mathrm{O}$, which was in agreement with XRD analysis. Similarly, deconvoluted Ni2p band (Figure 13) was resolved to give another peak at 872.96 which was assigned to $\mathrm{Ni}-\mathrm{M}(\mathrm{BE})$.
The O1s peak at $530 \mathrm{eV}$ (Figure 14) may have resulted from adsorbed oxygen [21]. There were no XPS peaks for $\mathrm{NiO}$, $\mathrm{Ni}_{2} \mathrm{O}_{3}$, and $\mathrm{Ni}(\mathrm{OH})_{2}$, showing that $\mathrm{Ni}$ was not oxidized to the oxides or hydroxide. A Comparison of the relative areas of integrated intensity showed that $\mathrm{Ni}^{0}$ was a predominant component of the outer surface of the synthesized core-shell nanoparticles.

\section{Conclusion}

The synthesis of silver nickel nanobimetallic particles by coprecipitation from nonaqueous and aqueous solutions with inorganic source precursors and polymer matrix was successfully accomplished. Subsequently, characterization of the prepared nanocomposites was done using optical spectroscopy, electron microscopy, X-ray diffraction (XRD), and $\mathrm{X}$-photoelectron spectroscopy. The deconvolution of XPS high resolution and detailed surface elucidation of $\mathrm{Ag} / \mathrm{Ni}$ bimetallic particles in polymer and polyol ligands revealed that their surfaces consisted of both metals which resulted into alloy or core-shell formation. Their binding energies were established showing that $\mathrm{M}-\mathrm{Ni}$ and $\mathrm{Ag}-\mathrm{O}$ bonds were formed at the corresponding energy intervals of 872.96 and $375.60 \mathrm{eV}$. The kinetic of anisotropic particle growth shows 

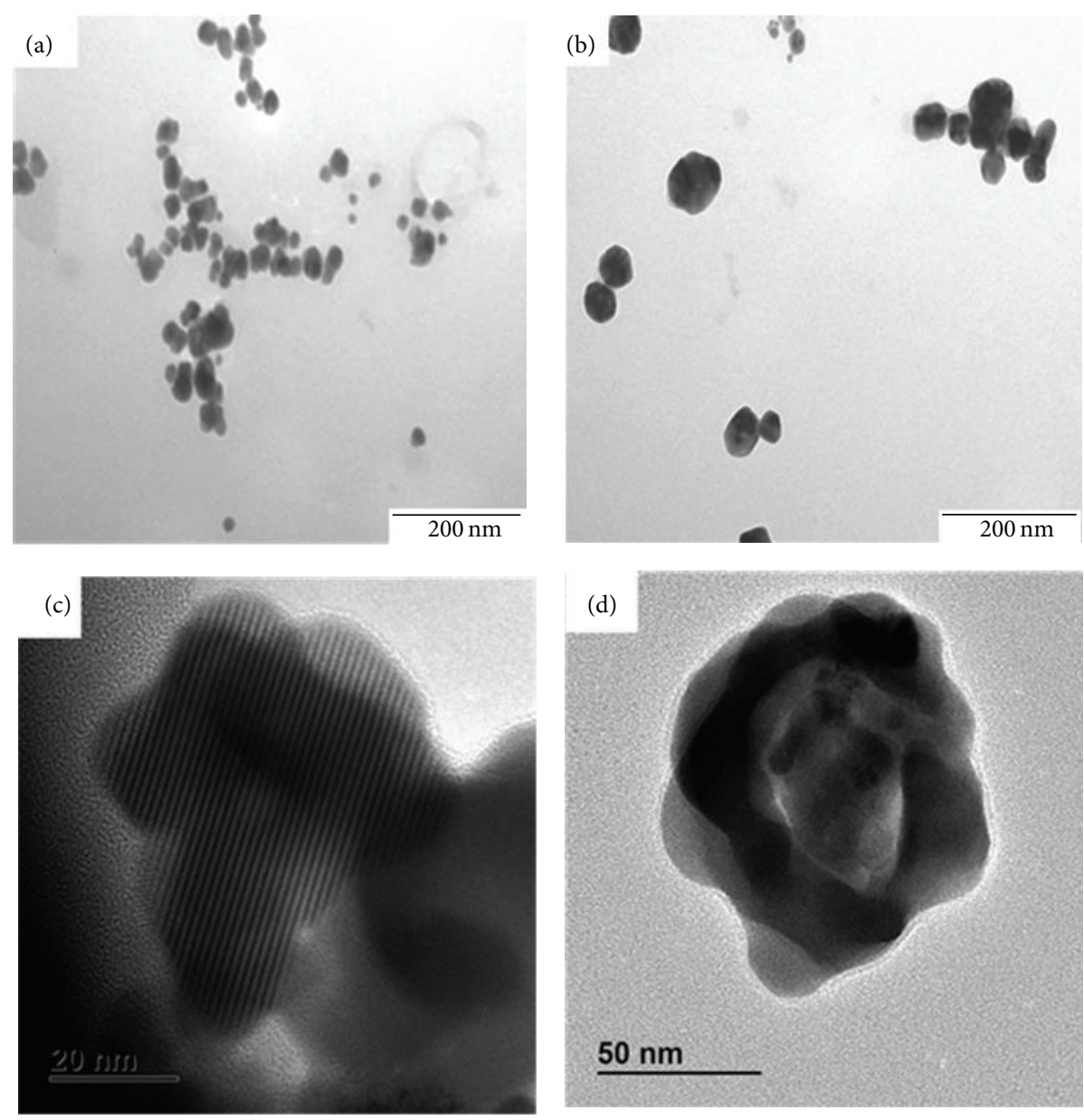

Figure 8: TEM images of AgNi NPs stabilized with (a) PVP/DEG at $200^{\circ} \mathrm{C}, 2 \mathrm{~h}$; (b) PVP/EG at $160^{\circ} \mathrm{C}, 3 \mathrm{~h}$; (c and d) corresponding HRTEM images of $(a$ and $b)$.
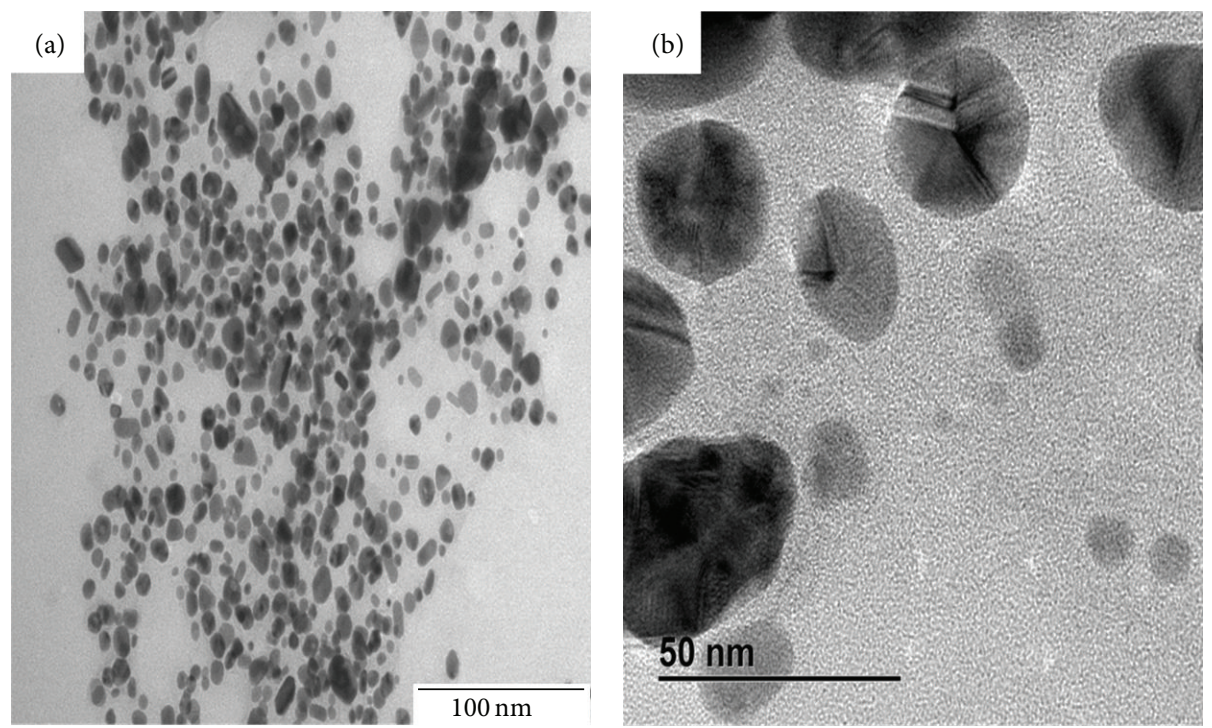

FIgure 9: (a) TEM image of AgNi NPs; (b) HRTEM image of AgNi NPs functionalized with PVP/PET at $90^{\circ} \mathrm{C}, 4 \mathrm{~h}$. 


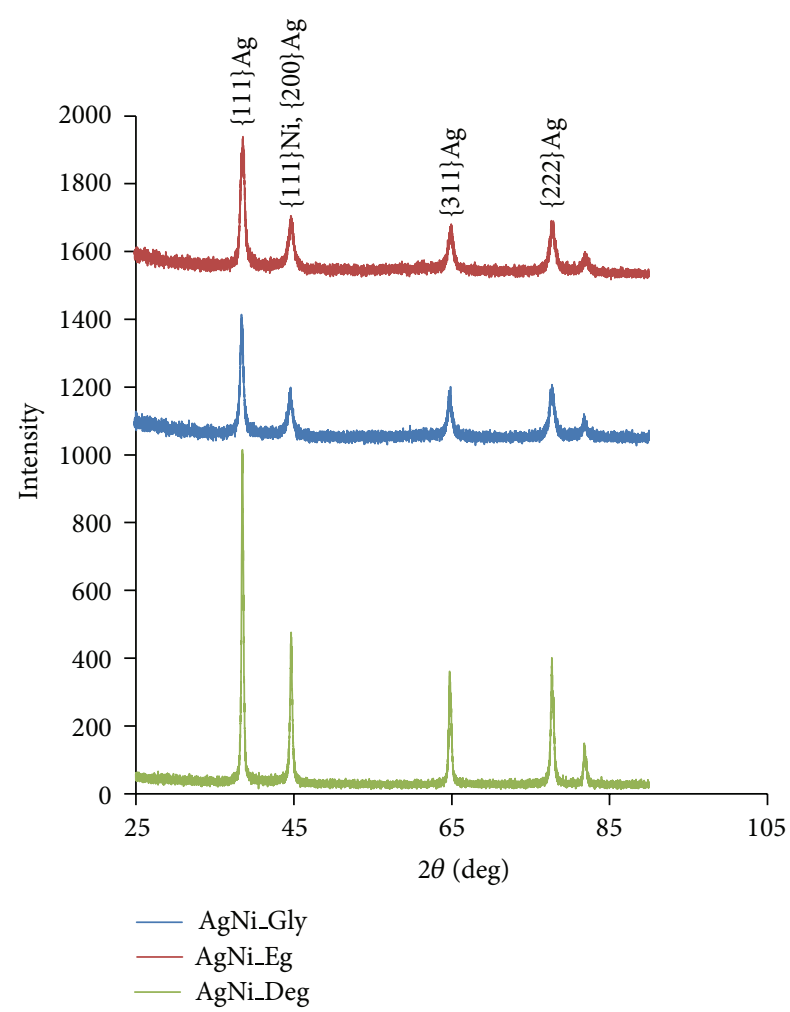

FIGURE 10: XRD patterns of AgNi nanoparticles stabilized with $\mathrm{PVP} / \mathrm{DEG}$ at $190^{\circ} \mathrm{C}, 2 \mathrm{~h}$; PVP/EG at $160^{\circ} \mathrm{C}, 3 \mathrm{~h} ; \mathrm{PVP} / \mathrm{GLY}$ at $160^{\circ} \mathrm{C}$, $2 \mathrm{~h}$.

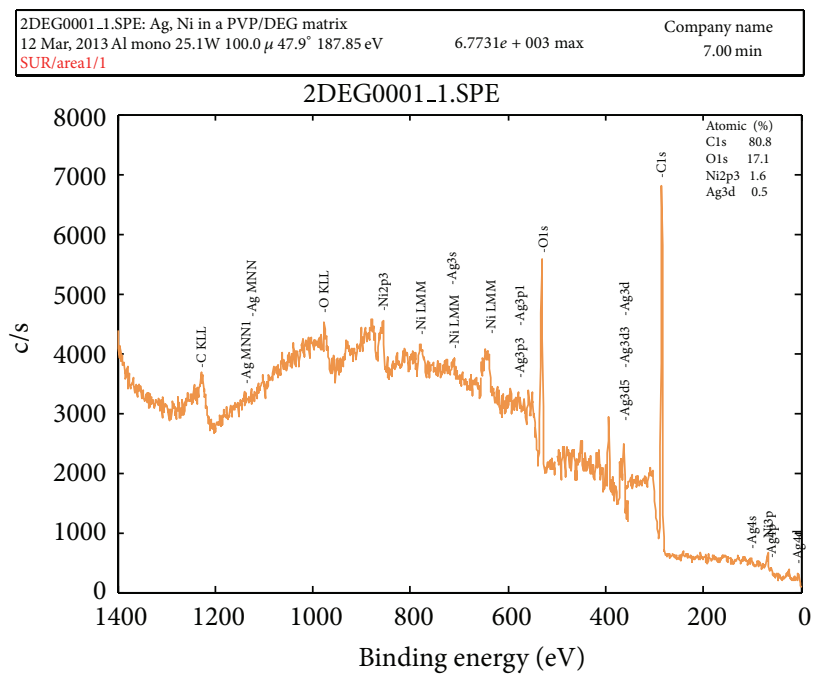

FIGURE 11: XPS spectrum of AgNi nanoparticles stabilized with $\mathrm{PVP} / \mathrm{DEG}$ at $200^{\circ} \mathrm{C}, 2 \mathrm{~h}$.

that, for alloy formation, the diffusion coefficients need to be many orders of magnitude larger than those of the bulk materials [22].

The $2 \theta$ reflections for AgNi diffraction pattern showed a relative shift to higher $2 \theta$ values corresponding to $\{111\}$ planes possibly overlapped with that for the $\{200\}$ planes of $\mathrm{Ag}$ at $2 \theta=44.54^{\circ}$. Meanwhile, for alloy formation as in the case of $\mathrm{Ag} / \mathrm{Ni}$, the addition of $\mathrm{Ag}$ causes clear shifts of the $\mathrm{Ni}$

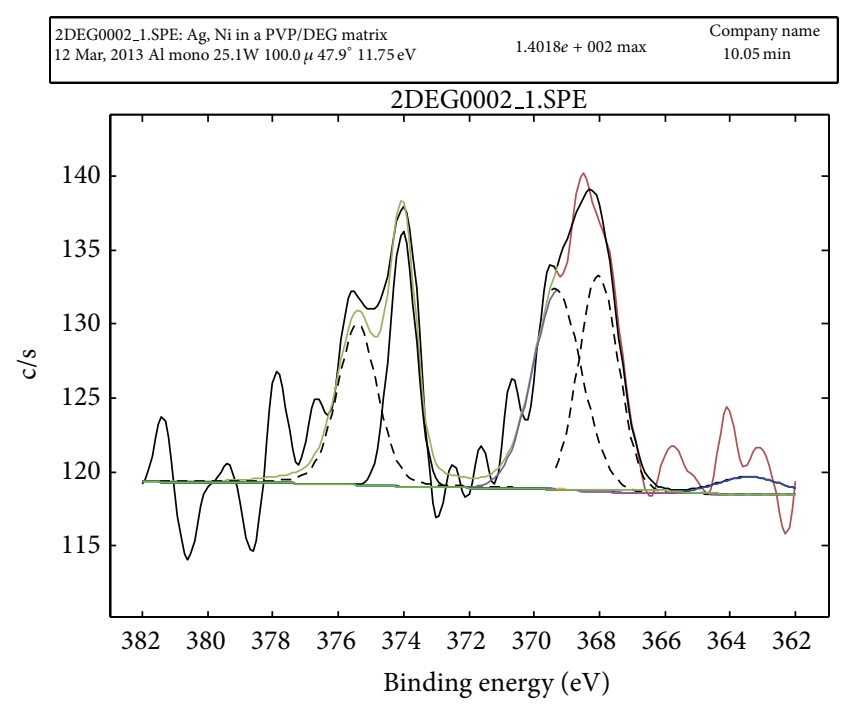

FIgURE 12: High resolution scan of Ag core levels.

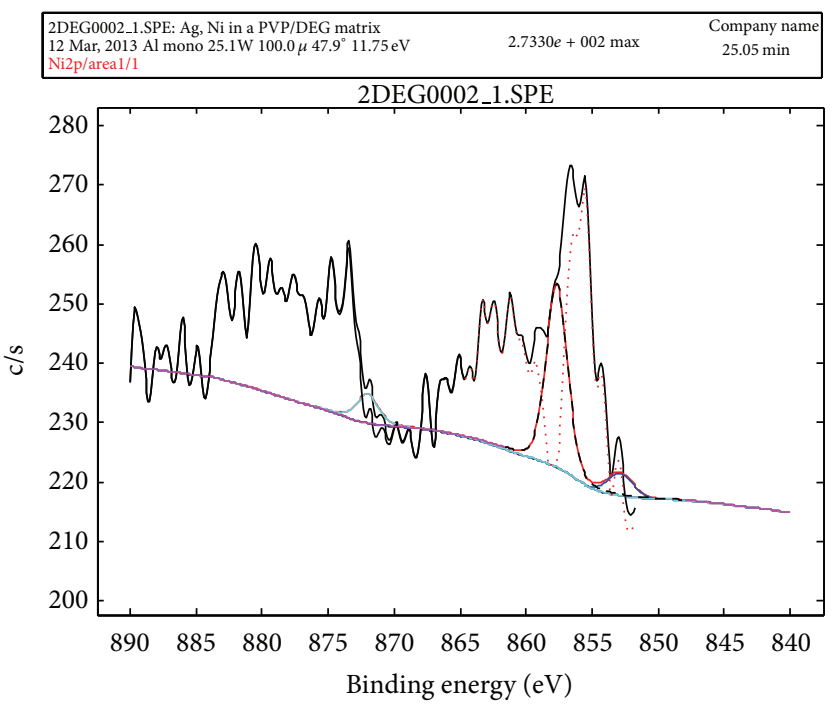

FIGURE 13: High resolution scan of Ni2p core levels.

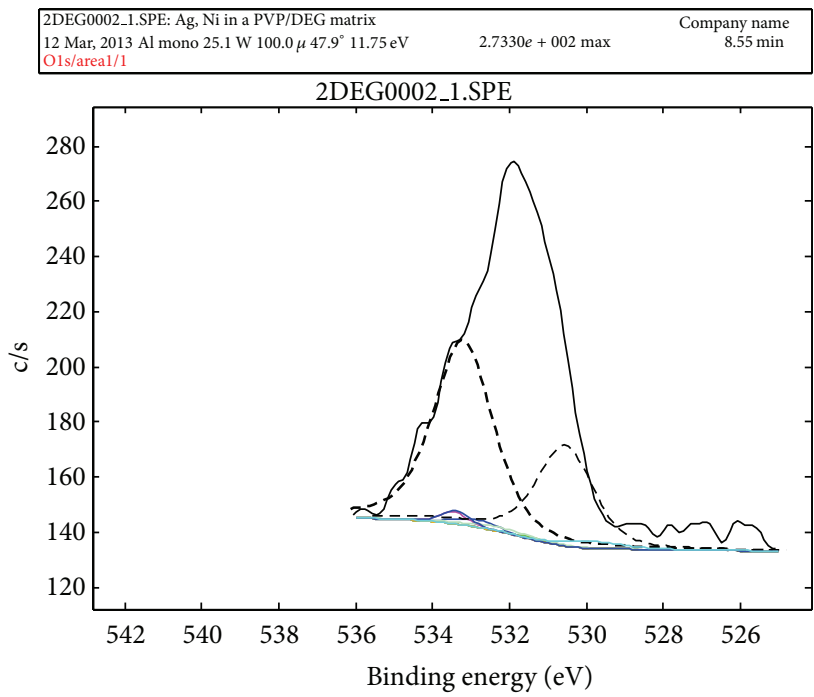

FIGURE 14: High resolution scan of O1s core levels. 
$\{111\}$ peaks towards the Ag peaks, following the effect that the higher the Ag content, the more shift, which indicated that the alloying of bimetallic $\mathrm{Ag} / \mathrm{Ni}$ occurred.

\section{Conflict of Interests}

The authors declare that there is no conflict of interests regarding the publication of this paper.

\section{Acknowledgments}

The authors are grateful to the National Research Foundation (NRF) and the Department of Science and Technology (DST) South Africa. The authors also thank Dr. James Wesley-Smith of the Electron Microscopy Unit, University of KwazuluNatal, for electron microscopy (TEM) measurements and CSIR, Pretoria for HRTEM facility, and Professor Hendrick Swart of the University of Freestate, Bloemfontein, South Africa, for XPS measurement.

\section{References}

[1] Q. Xiao, Z. Yao, J. Liu, R. Hai, H. Y. Oderji, and H. Ding, "Synthesis and characterization of Ag-Ni bimetallic nanoparticles by laser-induced plasma," Thin Solid Films, vol. 519, no. 20, pp. 7116-7119, 2011.

[2] V. Abdelsayed, G. Glaspell, M. Nguyen, J. M. Howe, and M. S. ElShall, "Laser synthesis of bimetallic nanoalloys in the vapor and liquid phases and the magnetic properties of PdM and PtM nanoparticles ( $\mathrm{M}=\mathrm{Fe}$, Co and $\mathrm{Ni})$," Faraday Discussions, vol. 138, pp. 163-180, 2008.

[3] S. Kishore, E. Tamio, C. Sang-Geun, K. Jongryoul, J. P. Tae, and P. Reji, "Single step synthesis and optical limiting properties of $\mathrm{Ni}-\mathrm{Ag}$ and $\mathrm{Fe}-\mathrm{Ag}$ bimetallic nanoparticles," Optical Materials, vol. 35, no. 5, pp. 860-867, 2013.

[4] L. Xia, X. Hu, X. Kang, H. Zhao, M. Sun, and X. Chen, "A onestep facile synthesis of Ag-Ni core-shell nanoparticles in waterin-oil microemulsions," Colloids and Surfaces A, vol. 367, no. 1-3, pp. 96-101, 2010.

[5] C. Lee and D. Chen, "Large-scale synthesis of Ni-Ag coreshell nanoparticles with magnetic, optical and anti-oxidation properties," Nanotechnology, vol. 17, no. 13, pp. 3094-3099, 2006.

[6] N. Toshima, K. Kushihashi, T. Yonezawa, and H. Hirai, "Colloidal dispersion of palladium-platinum bimetallic clusters protected by polymers, preparation and application to catalysis," Chemistry Letters, vol. 18, no. 10, pp. 1769-1772, 1989.

[7] N. Toshima, T. Yonezawa, and K. Kushihashi, "Polymer-protected palladium-platinum bimetallic clusters: preparation, catalytic properties and structural considerations," Journal of the Chemical Society, Faraday Transactions, vol. 89, no. 14, pp. 25372543, 1993.

[8] N. Toshima, M. Kanemaru, Y. Shiraishi, and Y. Koga, "Spontaneous formation of core/shell bimetallic nanoparticles: a calorimetric study," Journal of Physical Chemistry B, vol. 109, no. 34, pp. 16326-16331, 2005.

[9] F. M. Veronese, "Peptide and protein PEGylation: a review of problems and solutions," Biomaterials, vol. 22, no. 5, pp. 405417, 2001.
[10] G. G. Kumar, B. Karunagaran, K. S. Nahm, and R. N. Elizabeth, "Nanometer sized silver particles embedded silica particlesspray method," Nanoscale Research Letters, vol. 4, no. 5, pp. 452458, 2009.

[11] M. R. Hoffmann, S. T. Martin, W. Choi, and D. W. Bahnemann, "Environmental applications of semiconductor photocatalysis," Chemical Reviews, vol. 95, no. 1, pp. 69-96, 1995.

[12] S. S. Kim, S. I. Na, J. Jo, D. Y. Kim, and Y. C. Nah, "Plasmon enhanced performance of organic solar cells using electrodeposited Ag nanoparticles," Applied Physics Letters, vol. 93, no. 7, Article ID 073307, 2008.

[13] K. Awazu, M. Fujimaki, C. Rockstuhl et al., "A plasmonic photocatalyst consisting of silver nanoparticles embedded in titanium dioxide," Journal of the American Chemical Society, vol. 130, no. 5, pp. 1676-1680, 2008.

[14] M. D. Irwin, D. B. Buchholz, A. W. Hains, R. P. H. Chang, and T. J. Marks, " $p$-Type semiconducting nickel oxide as an efficiencyenhancing anode interfacial layer in polymer bulk-heterojunction solar cells," Proceedings of the National Academy of Sciences of the United States of America, vol. 105, no. 8, pp. 2783-2787, 2008 .

[15] M. L. Wu and L. B. Lai, "Synthesis of Pt/Ag bimetallic nanoparticles in water-in-oil microemulsions," Colloids and Surfaces A, vol. 244, no. 1-3, pp. 149-157, 2004.

[16] D. H. Chen and S. R. Wang, "Protective agent-free synthesis of $\mathrm{Ni}-\mathrm{Ag}$ core-shell nanoparticles," Materials Chemistry and Physics, vol. 100, no. 2-3, pp. 468-471, 2006.

[17] Joint Committee on Powder Diffraction Standards, Swarthmore, Pa, USA, 1974.

[18] D. E. Zhang, X. M. Ni, H. G. Zheng, Y. Li, X. J. Zhang, and Z. P. Yang, "Synthesis of needle-like nickel nanoparticles in waterin-oil microemulsion," Materials Letters, vol. 59, no. 16, pp. 2011$2014,2005$.

[19] F. Liu, J. Y. Lee, and W. Zhou, "Template preparation of multisegment PtNi nanorods as methanol electro-oxidation catalysts with adjustable bimetallic pair sites," Journal of Physical Chemistry B, vol. 108, no. 46, pp. 17959-17963, 2004.

[20] J. F. Moulder, W. F. Stickle, P. E. Sobol, and K. D. Bomben, in Handbook of X-Ray Photoelectron Spectroscopy, J. Chastain and R. C. King Jr., Eds., Physical Electronics Inc., Chanhassen, Minn, USA, 1995.

[21] X. Peng, Y. Zhang, J. Zhao, and F. Wang, "Electrochemical corrosion performance in $3.5 \% \mathrm{NaCl}$ of the electrodeposited nanocrystalline Ni films with and without dispersions of Cr nanoparticles," Electrochimica Acta, vol. 51, no. 23, pp. 4922-4927, 2006.

[22] M. Avrami, "Kinetics of phase change-I: general theory," The Journal of Chemical Physics, vol. 7, no. 12, pp. 1103-1112, 1939. 

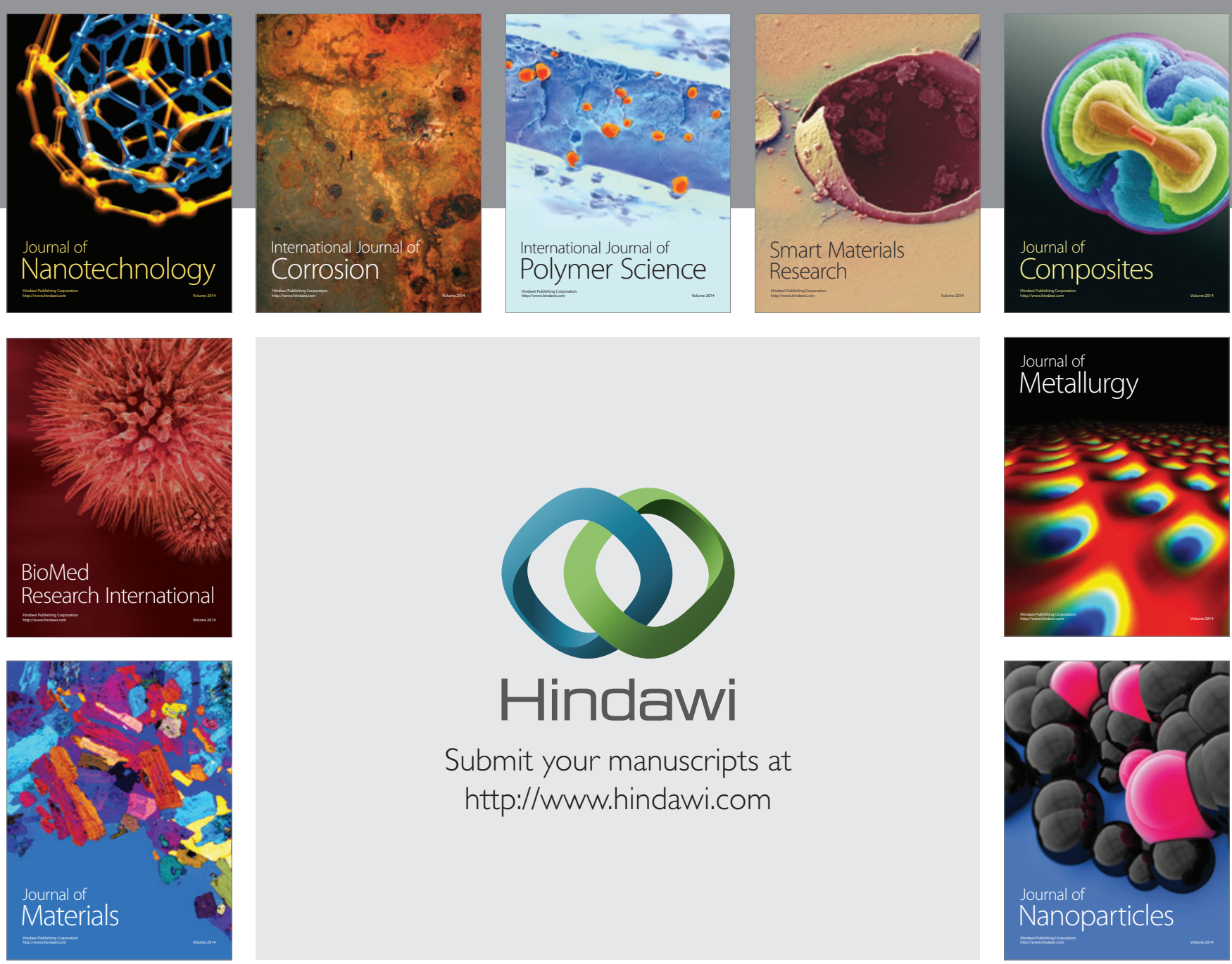

Submit your manuscripts at http://www.hindawi.com
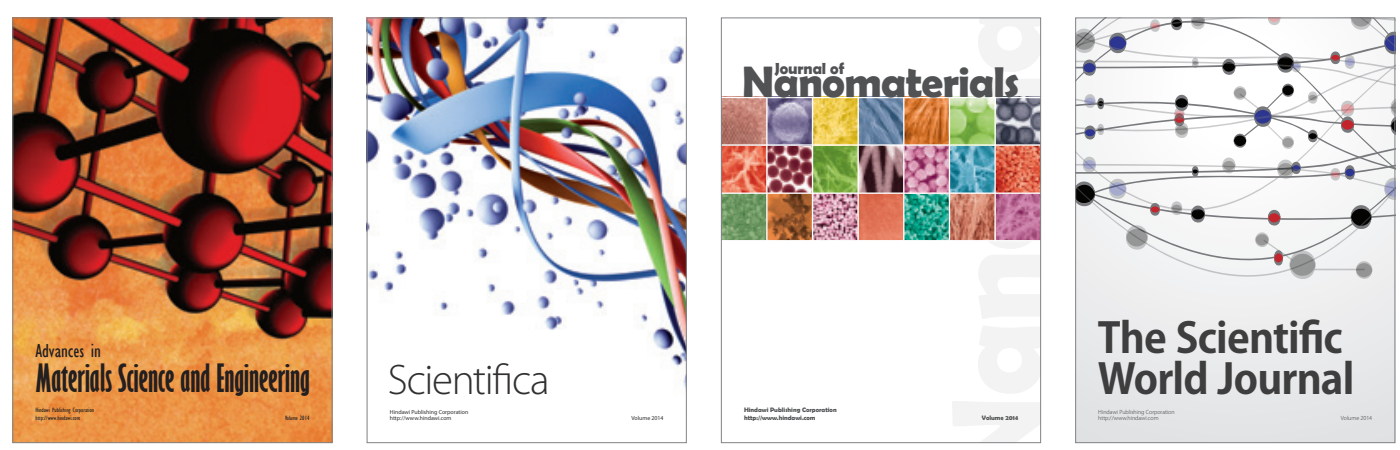

\section{The Scientific World Journal}
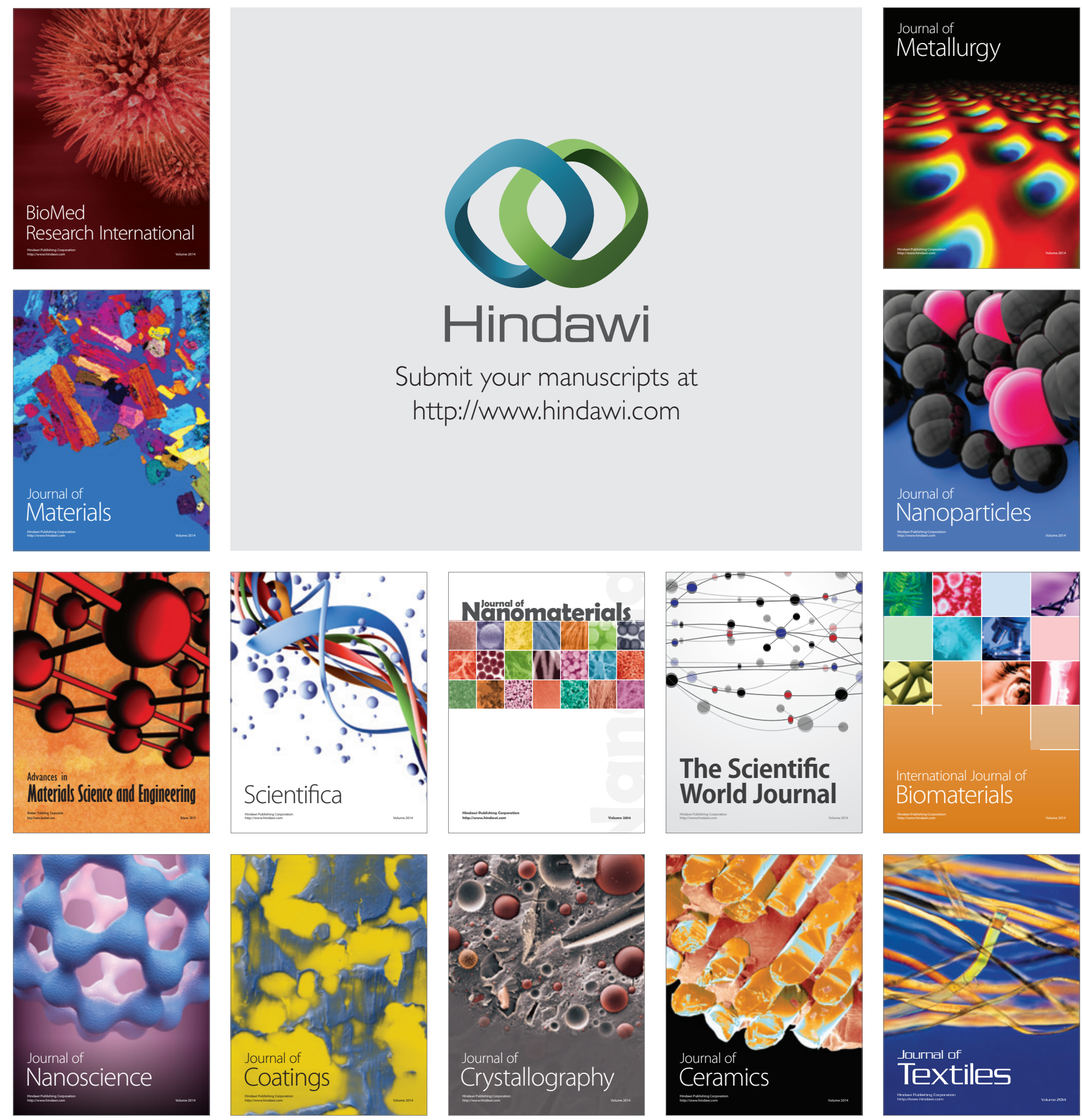